four member libraries. Their paper discusses how the member institutions build and maintain record sets for commonly held electronic collections for the benefit of the consortium.

\section{Editorial Board Changes}

The membership of the LRTS editorial board changes at the conclusion of the ALA Annual Conference. I want to take this opportunity to thank outgoing board members Elise Calvi, Birdie MacLennan, and Elaine Westbrooks for their fine work and input. Each of them has served two two-year terms, and they will be missed. Oksana Zavalina concluded a one-year term as an intern, and she will continue as a board member. I appreciate her insightful reviews and perspective. I want to acknowledge the tremendous contributions (both in terms of reviews and discussions) of continuing board members Everett Allgood, David Banush, Sian Brannon, Steven Carrico, Christopher Cronin, Nadine Ellero, Andrew Hart, Steven Knowlton, Philip Schreur, Anne Sleeman, Lori Terrill, and Lynn Wiley. You have helped me to grow into my new role as LRTS editor. I also acknowledge the contributions of Book Review Editor Norm Medeiros, ALCTS News Editor Alice Platt, and ALCTS Staff Liaison Christine McConnell. They provide balance and an additional perspective for our work. Lastly, it is with great pleasure that I welcome new board members Karen E. K. Brown, Lisa German, Virginia (Ginger) Williams, and intern Barry Brown. I look forward to working with them.

\title{
Errata
}

Information in v. 57, no. 3 for the author of "Identifying Significant Changes in Serials with Title Changes in the Recognition of New Works" is provided incorrectly on the cover and page 136. The author's name is Mavis B. Molto. We apologize for the error.

Information for one of the authors of "PDA Consortium Style: The CU Myilibrary Cataloging Experience" is incorrectly provided on the cover and page 164. The correct form of one of the author's name is Wen-ying Lu. We apologize for the error. 